\title{
MANAGED CARE PHARMACY AT THE ST. LOUIS COLLEGE OF PHARMACY
}

The rapidly changing health care environment challenges all pharmacy organizations, including colleges of pharmacy, to adapt so that practitioners will be able to respond to the opportunities in managed care. The St. Louis College of Pharmacy is addressing this issue by giving both pharmacists and pharmacy students additional opportunities to learn more about the health care system and managed care pharmacy.

\section{EDUCATIONAL PROGRAMS FOR PRACTITIONERS}

Beginning in 1996, the St. Louis College of Pharmacy will offer both a Certificate in Managed Care Pharmacy and a Master of Science (M.S.) in Managed Care Pharmacy. These programs are designed to prepare pharmacists to assume managerial positions in today's managed health care environment. To earn the certificate, participants must satisfactorily complete four of five graduate-level courses: Health Economics, Health Care and Public Policy, Principles of Managed Care Pharmacy, Current Topics in Managed Care Pharmacy, and Pharmacoeconomics and Outcomes Management.

Pharmacists who wish to earn a master of science degree can enroll in a 12 course, 36-credit hour curriculum. As a graduation requirement, students are expected to develop a portfolio documenting successful completion of several projects such as a business plan for a new managed care pharmacy product or service, formulary decision-making, drug-use evaluation, disease-management protocols, pharmacoeconomic analyses, and managed care research projects. Through the program, students will achieve specific goals such as:

A Analyzing and evaluating typical problems in today's health care environment using financial, economic, marketing, and information-systems principles.

A Explaining epidemiologic, statistical, and research design methods found in current health care literature.

$\Delta$ Using computers to analyze data and quantify health outcomes.

$\Delta$ Recommending changes in health care organizations in terms of structure, systems, strategies, and management styles that will provide effective and efficient pharmaceutical care.

$\Delta$ Understanding the evolution of trends in the U.S. health care system and the principles of managed care.

A Assessing health outcomes and answering drug-use questions using a populationbased database.

$\boldsymbol{\Delta}$ Designing and planning the implementation of pharmaceutical care models and disease state management programs.

A Applying pharmacoepidemiology, pharmacoeconomics, and quality of life techniques in a managed care environment.

Specific courses include Health Economics, Financial Management, Health Services Marketing, Principles of Management, Health Care and Public Policy, Managed Care Research Methods (two courses), Principles of Managed Care Pharmacy, Current Topics in Managed Care Pharmacy, and Pharmacoeconomics and Outcomes Management. Additionally, a number of electives are available, such as Business Law, Computer Information Management, and Advanced Leadership. Managed care experiential programs and research projects are also available. Students who already work as full-time pharmacists may take evening classes or choose whether to participate in the M.S. program on a fulltime or part-time basis within a few years.

Eight faculty members have first-hand experience in managed care, computer information management, drug-use review, pharmacoeconomics and outcomes research, and international pharmaceutical marketing. One faculty member holds a dual position with the College and a local pharmacy benefit management company as an outcomes researcher.

\section{EDUCATIONAL PROGRAMS FOR UNDERGRADUATE STUDENTS}

Since the St. Louis College of Pharmacy is a private college offering a five-year bachelor of science and a sixyear doctor of pharmacy program, it enjoys considerable flexibility in designing and sequencing courses and other curricular decision-making This flexibility has allowed the College to adjust to meet current needs in the health care marketplace.

Before 1993, a one credit-hour Health Care Systems course was taught to secondyear (preprofessional) students. Because of the limited exposure of these students to the health care system, and the large amount of material to cover, one hour was insufficient. Consequently, Health Care Systems was dropped and much of the course material was transferred to a third-year (first professional year) pharmacy management course that was expanded from three to four credithours. This change allowed discussion of health economics, principles of insurance, third-party and managed care programs, formulary management, pharmacoeconomics, drug-use review, and other related topics. Upon completion of the undergraduate

Continued on page 442 
management sequence, students should be able to:

$\Delta$ Use marketing concepts to explain how pharmacists can collaborate with managed care organizations to satisfy mutual organizational objectives.

$\Delta$ Evaluate managed care contracts.

$\Delta$ Understand basic concepts of risk management.

$\Delta$ Apply basic pharmacoeconomic principles, such as cost-benefit and cost-effectiveness, to solve case studies.

A Apply basic outcomes management and disease management concepts to solve case studies.

$\Delta$ Understand the basic principles of pharmacoepidemiology.

Managed care topics are also discussed in other courses, including Management and Organizational Behavior, Sociology of Medicine, and Pharmacy Entrepreneurship. A new course, Pharmacoeconomics and Outcomes Management, is currently being considered. At the same time, two courses (Pharmacy Management and Management and Orga- nizational Behavior) are being coordinated and realigned to cover more health economics, health care financing, and managed care topics. Other attempts to increase undergraduate students' exposure to managed care include elective clerkship rotations, a managed care residency through a local managed care organization, and pharmacoeconomic examples incorporated in therapeutics case studies.

Both at the undergraduate and graduate levels, the St. Louis College of Pharmacy is adapting its curriculum to enable students and pharmacists to practice successfully in the managed care environment.

Kenneth W. Schafermeyer, Ph.D. Associate Professor Pharmacy Administration

Brenda R. Motheral, M.B.A., Ph.D. Assistant Professor Pharmacy Administration

St. Louis College of Pharmacy 4588 Parkview Place St. Louis, MO 63110 